\title{
Porosity Measurement of Iron Oxide by Using Computer Vision System
}

\author{
A. A. Abo El-Nasr ${ }^{1,3}$, A. Saleh ${ }^{2}$ and A. A. Alshennawy ${ }^{1,4}$ \\ ${ }^{1}$ Mechanical Engineering Department, Engineering College, Taif University, Taif 21974, KSA. \\ ${ }^{2}$ Electrical Engineering Department, Engineering College, Taif University, Taif 21974, KSA. \\ ${ }^{3}$ Department of Production Engineering and Design, College of Engineering, Menoufia University, Shebin El-Kom, Menoufia, Egypt. \\ ${ }^{4}$ Department of Production Engineering and Design, College of Engineering, Tanta University, Tanta, Egypt.
}

\begin{abstract}
In this work, a proposed Computer Vision System (CVS) has been applied to measure the porosity of iron oxide $\left(\mathrm{Fe}_{3} \mathrm{O}_{4}\right)$ specimens. Measurement of the porosity using CVS reduces time, effort and cost compared to the conventional methods. $\mathrm{Fe}_{3} \mathrm{O}_{4}$ was received from iron rolling process in the form of thin layer, and then converted to powder by grinding process and filtering by $200 \mu \mathrm{m}$ sieve. $\mathrm{Fe}_{3} \mathrm{O}_{4}$ specimens were then manufactured by powder metallurgy (PM) technique using steel die subjected to a compression load $(300 \mathrm{KN})$ to form cylindrical discs with $27 \mathrm{~mm}$ diameter and $10 \mathrm{~mm}$ height. Optical microscope with digital camera has been used in capturing images of the surfaces of $\mathrm{Fe}_{3} \mathrm{O}_{4}$ specimens. The proposed CVS uses k-means algorithms, which divide the intended surfaces into distinct regions and by computing the ratio between these regions, the specimen porosity is obtained. Layers of the specimens are removed to measure the average porosity inside the specimens. The average value of porosity of specimens has been obtained for the original specimen and its mean value is $\sim 26.39 \%$. In comparison, the porosity computed by CVS was very close to that obtained using conventional method, which confirms the efficiency of this technique.
\end{abstract}

Keywords: Porosity, Computer vision, Iron oxide, Image analysis, Powder metallurgy

\section{INTRODUCTION}

Porosity is a characteristic in solid materials that describes the amount of pores relative to the rest of the material. Porosity is expressed by measuring the proportion of either connected or disconnected pores to total mass of the material. Porosity in metallic materials is of great importance because of their relevance on material's density, strength, brittleness and fracture toughness [1]. The microstructure of the metallic materials and their mechanical properties are strongly related. In this context, porosity is one of the coefficients that affect the elastic constants and other properties of the produced materials. Examples of the industrially porous materials include; catalysts materials, ceramic and construction materials, pharmaceutical products, pigments, membranes, sorbents, sensors, electrodes, fuel cells and active components in batteries, and gas and oil bearing stratum and rocks [2].

Recently, in computer science, some projects have used image analysis to characterize the porosity behavior in different materials [3,4]. CVS provides key inputs for materials inspection for quality control as well as predicting materials properties from the digital analysis of microstructure images [1]. CVS and digital image analysis have a key role to play in the field of material manufacturing and quality control. Measurement of porosity using CVS reduces time, effort and money compared to the conventional methods, with reasonable accuracy. The images analysis of engineering materials provides important information for materials properties using an easy and simple means. Examples of images analysis applications are structure quantification $[1,5]$ and mechanics of porous media [6,7]. Porosity can be estimated by computing volumetric measurements of core specimens from image analysis, which is pores size estimation of a small sample. This field is conducted towards the porosity measurement of the specimens, because it offers the basic concepts for understanding [4]. Classification and clustering algorithms has been extensively used to isolate the region of interest for the input images [8]. Many clustering models have been used to identify and extract the concerned region such as centroid-based clustering, distribution based clustering, connectivity-based clustering and density based clustering [911].

Iron oxide $\left(\mathrm{Fe}_{3} \mathrm{O}_{4}\right)$ is material used for corrosion resistance purposes. This material was selected as a model material for a high porosity material through which the relationship between the resulting porosity and its physical properties could be linked [12]. Very little has been published about this particular material regarding the measurement of porosity and predicting their behavior using the computer vision analysis.

In this study, a computer vision system (CVS) will be applied to compute the porosity of $\mathrm{Fe}_{3} \mathrm{O}_{4}$ specimens that were manufactured by powder metallurgy (PM) processes. Layers of the specimens are removed to the middle of the specimens to measure the average porosity inside them. A comparison between the average of porosity value estimated by this technique and that of the conventional method will be made.

\section{II.SPECIMENS MANUFACTURING AND POROSITY MEASUREMENT \\ II.I Material and Specimens Preparation}

The primary material used in this work was iron oxide $\left(\mathrm{Fe}_{3} \mathrm{O}_{4}\right)$ powder. The material was received in the form of iron oxide shells that were produced from the rolling processes of iron raw materials. As shown in Fig. 1 (a), the $\mathrm{Fe}_{3} \mathrm{O}_{4}$ shells have been extensively grinded and carefully filtered using sieve $200 \mu \mathrm{m}$. The powder produced was then distributed to specimens weighing $30 \mathrm{gm}$ each, Fig. 1 (b). PM processes 
have been performed for manufacturing $\mathrm{Fe}_{3} \mathrm{O}_{4}$ specimens in which a cylindrical die was designed and produced to compact the powder. As shown in Fig. 1 (c), the die has been placed on a hydraulic press and exposed to a compression load $300 \mathrm{kN}$ for 15 minutes and the powder has been pressed up to a height of $\sim 10 \mathrm{~mm}$. Then, the specimens have been subjected to two step sintering process in which they were heated in air in electric furnace to $100{ }^{\circ} \mathrm{C}$ for $24 \mathrm{hrs}$., and then they were exposed to $950{ }^{\circ} \mathrm{C}$ for 3 hrs., as shown in Fig. 1 (d) [12-14].

Fig. 2 (a) shows five typical specimens that were produced by PM and sintering process, with same dimensions. The surfaces of these specimens are carefully polished to a mirrorlike surface in order to capture number of images for microscopic analysis. Fig. 2 (b) shows a specimen after conducting two step sintering process and Fig. 2 (c) shows the specimen after polishing its surface to begin surface imaging and analysis. Optical Microscope (OM) has been employed to capture many images of the surfaces of $\mathrm{Fe}_{3} \mathrm{O}_{4}$ specimens and these were the main source of image analysis in CVS.
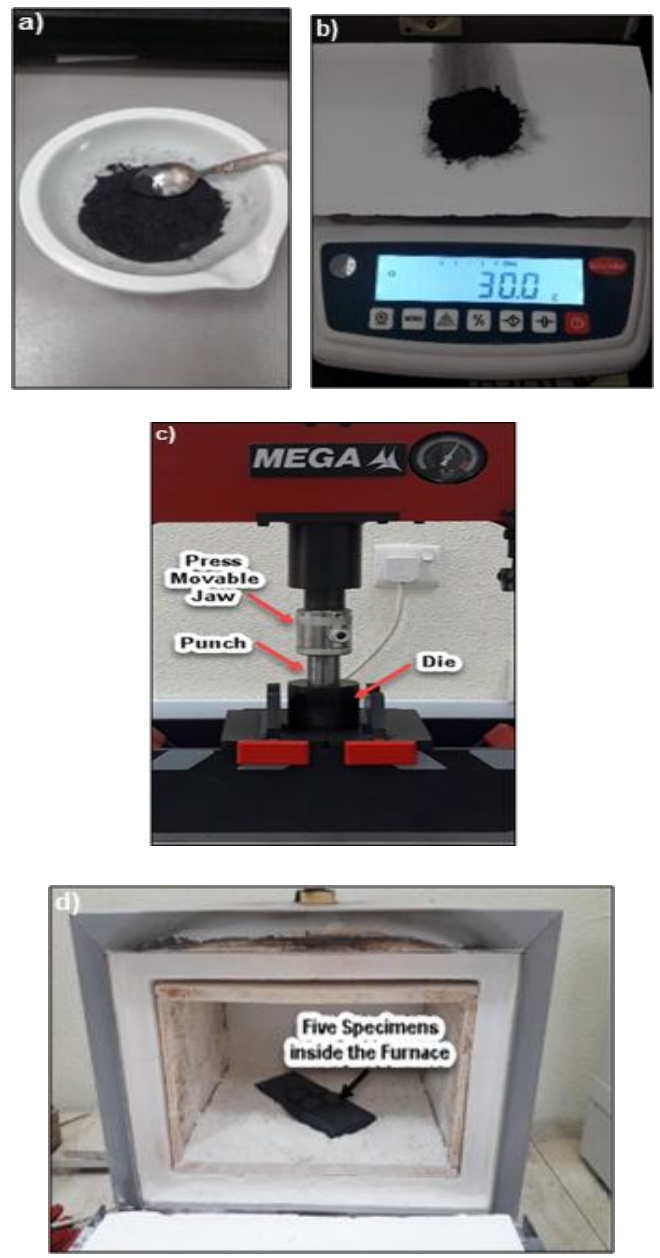

Fig. 1 Specimens processing; a) $\mathrm{Fe}_{3} \mathrm{O}_{4}$ powder after grinding and filtering using a $200 \mu \mathrm{m}$ sieve, b) Distributing the powder to samples, each is $30 \mathrm{gm}$., c) Hydraulic Press with die used in pressing $\mathrm{Fe}_{3} \mathrm{O}_{4}$ specimens, and d) Electric furnace used for sintering.
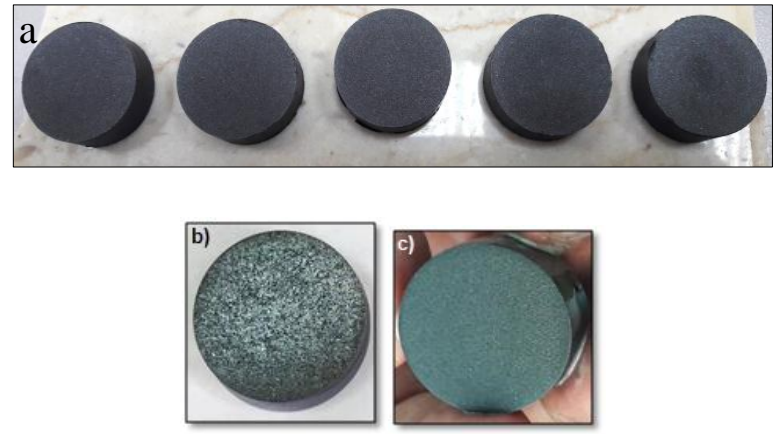

Fig. 2 a) $\mathrm{Fe}_{3} \mathrm{O}_{4}$ specimens manufactured using $\mathrm{PM}$ technique, b) Specimen after conducting two step sintering process, and c) Specimen after polishing its surface for imaging analysis

\section{II.II Calculation of the Porosity by Conventional Method}

In the following the porosity will be measured by a conventional method by calculating the true and apparent density of the specimens. The true density is calculated using one of the specimen and the apparent density is calculated using another one. Fig. 3 shows the procedure used in calculating true density of $\mathrm{Fe}_{3} \mathrm{O}_{4}$ specimen using Pycnometer. The steps start with weighing the empty Pycnometer, (named as step 1) and weighing the Pycnometer filled with distilled water, (named as step 2). Then, the difference between weights in step1 and step 2 is calculated which equals to the weight of water, (called Case 1).

Whereas, water density = water weight/volume of water $\left[\mathrm{gm} . / \mathrm{cm}^{3}\right]$, (named as step 3).

The specimen is then grinded and filtered to a size of $200 \mu \mathrm{m}$ using suitable sieve and then weighing $5 \mathrm{gm}$. of the specimen powder. $\mathrm{Fe}_{3} \mathrm{O}_{4}$ powder is placed in an empty and dry Pycnometer, and then the Pycnometer is filled with distilled water until two thirds of its volume $(100 \mathrm{~mL})$. After that the Pycnometer is boiled in a water bath about 3 hours. Then the Pycnometer is left to cool down and filled with distilled water. Then the whole Pycnometer is weighed including all items (Pycnometer + water + specimen powder $)$.

Calculate water weight, (called Case 2) = total weight (empty Pycnometer + specimen powder weight).

The difference between Case 1 and 2 is obtained. Volume of specimen powder $=$ weight difference in step 10/water density calculated in step 3. Specimen powder density (true density) $=$ specimen powder weight/specimen powder volume.

After completion of the previous steps, it was found that the value of the true density of $\mathrm{Fe}_{3} \mathrm{O}_{4}$ specimen is $4.95 \mathrm{gm} . / \mathrm{cm}^{3}$. 

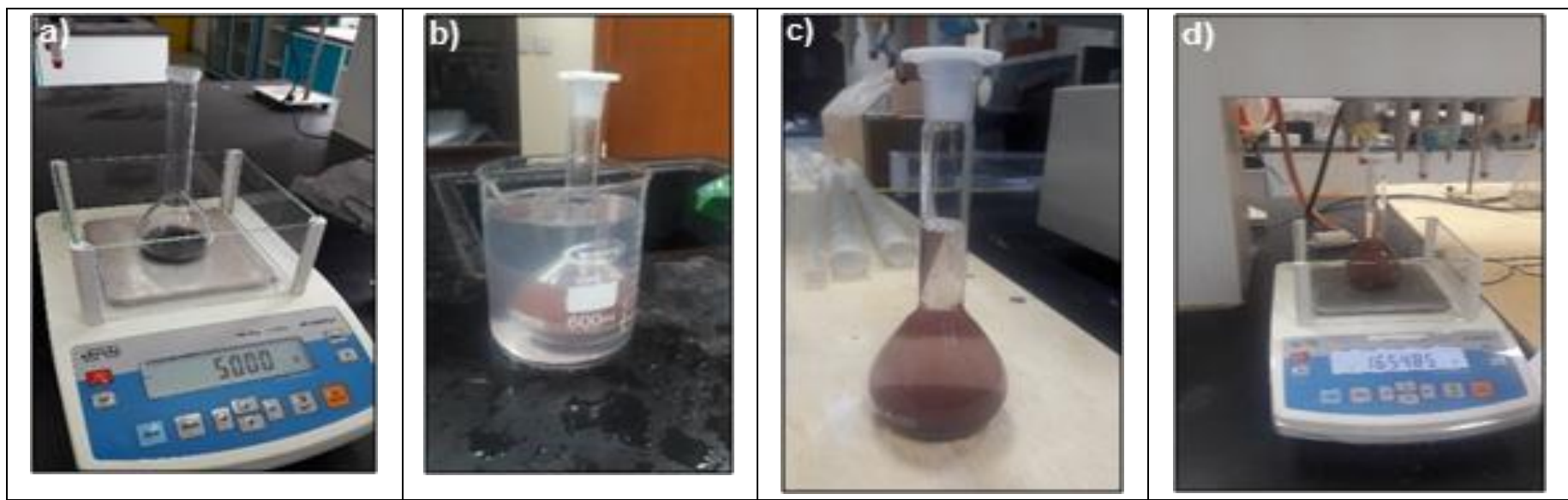

Fig. 3 Calculation of the true density, a) Weigh $5 \mathrm{gm}$ to calculate the true density using a $100 \mathrm{~mL}$ density, b) The boiling stage of the powder with water at 100 degrees for three hours, c) The powder and water after boiling and cooling, and d) Iron powder with water added.

Fig. 4 shows the procedures of calculating the apparent density of $\mathrm{Fe}_{3} \mathrm{O}_{4}$ specimen. The dry specimen is weighed using the scale, submerged in water for 24 hours, and then taken out and wiped with a cotton swab moistened with water to remove the remaining air bubbles on its surface. The specimen is weighed by hanging it with a thin thread in the scale's hook from the bottom (named step 2), Fig. 4.a. The specimen is weighed after being hanged by the thin thread and completely submerged in water, (named step 3), Fig. 4.b and c. The volume of the specimen $=$ the weight of the displacement liquid $=$ the weight calculated in step 2 - the weight calculated in step 3, (named step 4). Apparent density
$=$ the weight calculated in step $1 /$ the volume calculated in step 4. Based on these steps, the apparent density was found to be $3.63 \mathrm{gm} . / \mathrm{cm}^{3}$. The values of the two previous densities can be used to compute the porosity value of $\mathrm{Fe}_{3} \mathrm{O}_{4}$ specimen as follows:

True porosity $=\left(1-\frac{\text { Apparent density }}{\text { True density }}\right) \times 100$,

Then, True porosity $=\left(1-\frac{3.63}{4.95}\right) \times 100=26.67 \%$
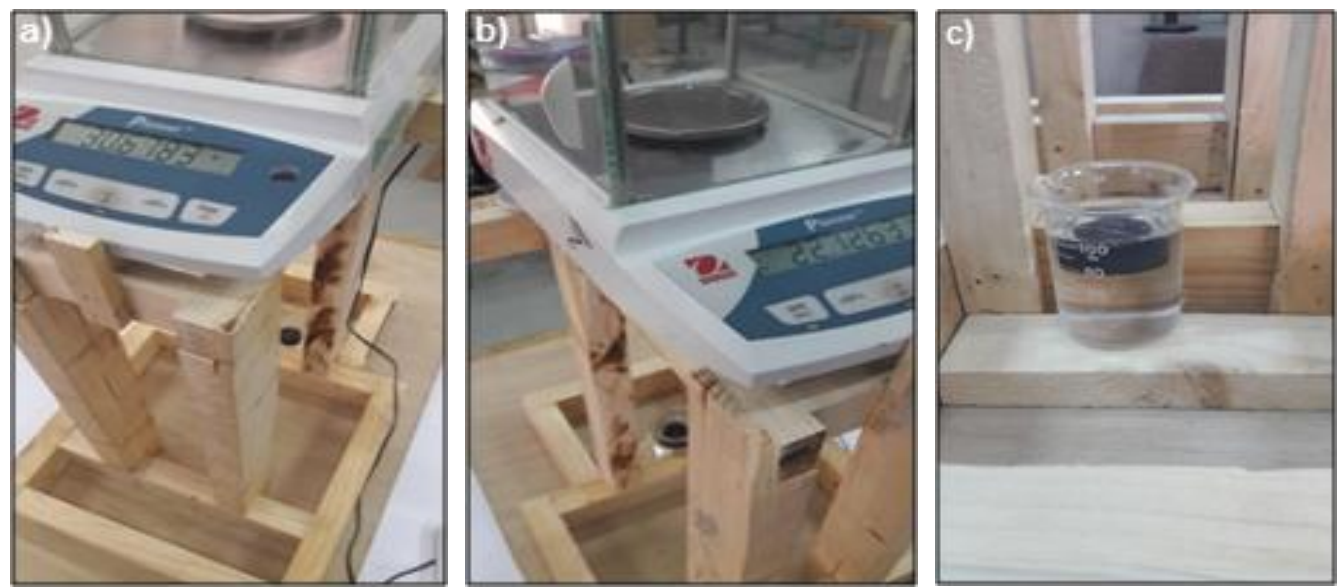

Fig. 4 Calculating the apparent density; a) Weighing $\mathrm{Fe}_{3} \mathrm{O}_{4}$ specimen suspended from the bottom of the sensitive scale, b) Weighing the specimen suspended in the balance from the bottom immersed in water, and c) The specimen suspended in the balance from the bottom immersed in water.

\section{IMAGE ANALYSIS PROCESS}

K-means algorithm has been employed in this study for porosity detection using CVS. This algorithm plays the main role in processing the images of $\mathrm{Fe}_{3} \mathrm{O}_{4}$ specimens for porosity measurement. The algorithm was designed to isolate the region of interest in the input images, based on pixels intensity value. The nature of the input image reveals that the most appropriate algorithm to extract the interesting region is $\mathrm{K}$ - means algorithm due to the input image contains gray colors that can be used for classifications $[10,11]$.

To extract and isolate the region of interest, the $\mathrm{Fe}_{3} \mathrm{O}_{4}$ images are clustered into clusters. Clustering is dividing the input image into regions which have some similar features in the entire inspected region [11]. The input image is then divided into regions with distinct colors. The colors of the input image reflect the regions that contain the region of interest. The color of the area in question is used to extract and compute its ratio 
to the rest of the inspected area. The steps and the performance of k-means algorithm and how it works are described in the following [15].

Let the pixels of the input image are:

$$
\boldsymbol{x}=\left\{\mathrm{x}_{\mathrm{i}}\right\}_{i=1}^{n} \quad 1 \leq \mathrm{i} \leq \mathrm{n},
$$

Where $\mathrm{n}$ is the dimension of the image or number of pixels, and

$$
\left\{\mathrm{xc}_{\mathrm{j}}\right\}_{j=1}^{\mathrm{m}} \quad 1 \leq \mathrm{j} \leq \mathrm{m}
$$

The centers of the clusters, and the number of cluster centers is $\mathrm{m}$.

Step 1: assume, $\mathrm{xc}_{1}=\mathrm{x}_{1}$

Step 2: Locate the outmost pixel from $\mathrm{x} 1$, and name it cluster center $\mathrm{Xc}_{2}$

$$
\left\|\mathrm{xc}_{2}-\mathrm{xc}_{1}\right\|=\max _{2 \leq \mathrm{i} \geq \mathrm{n}}\left\|\mathrm{x}_{\mathrm{i}}-\mathrm{xc}_{1}\right\|
$$

Step 3: Calculate the distance from the rest pixels to xci, for each one of these computations, chose maximum of the minimum distance:

$$
\begin{aligned}
& x^{\prime}=x-\left\{x c_{j}\right\} \\
& d=\left\|x_{i 0}-x_{j 0}\right\|=\max _{x_{i} \in x^{\prime}} \min _{1 \leq j \geq m}\left\|x_{i}-x_{j}\right\|
\end{aligned}
$$

Where $1 \leq$ jo $\leq \mathrm{m}$, and $\mathrm{x}_{\mathrm{io}} \in \mathrm{x}$ '

Step 4: The distance $d$ is examined and if it is a significant fraction of the distance between cluster centers, this pixel is named a new cluster center.

$$
\operatorname{mean}=\overline{\left\|\mathrm{xc}_{\mathrm{i}}-x c_{j}\right\|}
$$

where $1 \leq \mathrm{i}, \mathrm{j} \leq \mathrm{m}, \mathrm{i} \neq \mathrm{j}$

if $\left\{\begin{array}{c}\mathrm{d} \geq \mathrm{t}_{\mathrm{c}} \times \text { mean } \\ \text { otherwise }\end{array} \quad \begin{array}{c}\text { (newcluster) go to step } 3 \\ \text { (no more cluster) go to step } 5\end{array}\right.$

Where $t_{c}$ is the value of threshold that decides to create a new cluster or not.

Step 5: make all the rest pixels belong to the nearest cluster center. And for each $\mathrm{x}_{\mathrm{i}} \in \mathrm{X}$ ':

$$
\left\|x_{i}-\mathrm{xc}_{\mathrm{j}}\right\|=\min _{1 \leq \mathrm{j} \leq \mathrm{m}}\left\|\mathrm{x}_{\mathrm{i}}-\mathrm{xc}_{\mathrm{j}}\right\|
$$

Step 6: compute the pixel mean for each cluster. This means may then be utilized as the new cluster centers.

For $1 \leq \mathrm{j} \leq \mathrm{k}$, replace $\mathrm{c}_{\mathrm{j}}$ by

$$
x c_{j}=\frac{1}{p_{j}}\left(\sum_{j=1}^{p} x_{j}\right)
$$

Step 7: Rearrange the pixels $x^{\prime}$ between $\mathrm{xc}_{\mathrm{j}}$ (iter) cluster region, using the rule:

$$
x \in s_{j} \text { (iter) if } \| x-x c_{j}(\text { iter })\|\leq\| \mathrm{x}-x c_{i} \text { (iter) } \|
$$

Where, sj implies the set of pixels select cluster center is $x_{j}$, and $1 \leq \mathrm{i}, \mathrm{j} \leq \mathrm{m}, \mathrm{i} \neq \mathrm{j}$

iter: is required number of iterations to convergence.

Step 8: recalculate the new cluster centers

$$
x c_{j}(\text { iter }+1)=\frac{1}{p_{j}}\left(\sum_{j=1}^{p} x_{j}\right)
$$

So that the summation of the squared distance from all pixels in $s_{j}$ to the new cluster centers is minimized. In other words, the new cluster center $\mathrm{xc}_{\mathrm{j}}$ is calculated for minimizing the performance index.

$$
\boldsymbol{I}_{\boldsymbol{j}}=\sum_{\boldsymbol{x}_{\boldsymbol{i}} \in \boldsymbol{s}_{\boldsymbol{j}}(\text { iter })} \| \boldsymbol{x}_{\boldsymbol{i}}-\boldsymbol{x} \boldsymbol{c}_{\boldsymbol{j}}(\text { iter }+1) \|^{2}, \mathrm{j}=1,2, \ldots, \mathrm{m}
$$

Step 9: make sure of convergence that will be take placed if the cluster centers are unchanged:

if $\left\{\begin{array}{c}\mathrm{xc}_{\mathrm{j}}(\text { iter }+1)=\mathrm{xc}_{\mathrm{j}}(\text { iter }) 1 \leq \mathrm{j} \leq \mathrm{m} \text {, stop and terminate } \\ \text { otherwise }\end{array}\right.$

End.

Fig. 5 shows a typical example of the clustering process of the algorithm which has been applied to an input image. Fig. 5.a is the original image that has been processed to number of colors that defines the pores region as seen in Fig. 5.b. The following step is to isolate all colors except the color that represent the pores region. In this case, the light blue represents the region of interest that transformed in Fig. 5.c to white.

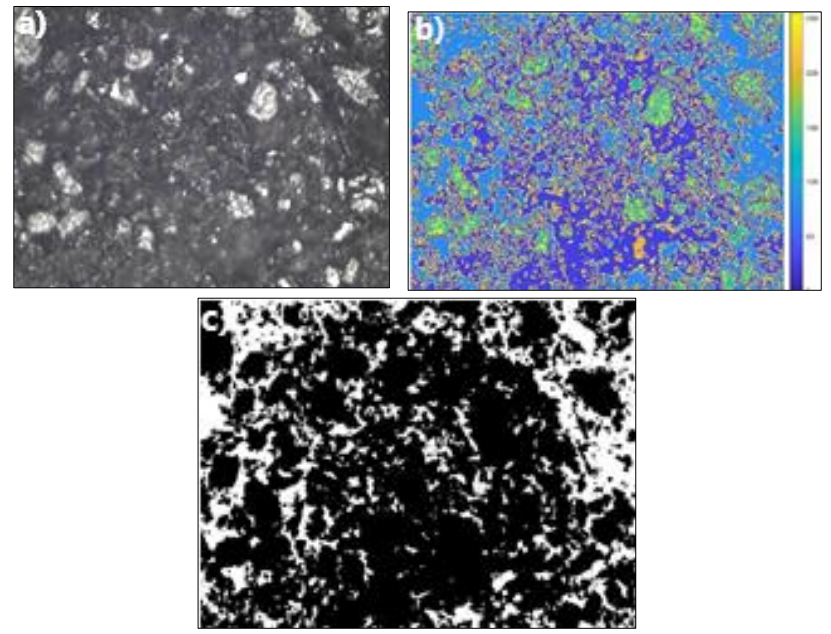

Fig. 5 Clustering and isolation processes: a) original image captured using OM, X100, b) the classification of captured surface into solid region and pore region (clustering process), and c) the porosity area in white color.

Where, $p$ is the number of pixels of cluster $j$. 


\section{RESULTS AND DISCUSSION}

In this study, two different cases have been considered for porosity computation using CVS. In these cases, the manufactured specimens have same diameter, $27 \mathrm{~mm}$, and two different thicknesses namely; 10 and $5 \mathrm{~mm}$. The K-means clustering algorithm is applied to the captured images. Five images have been captured for each case and they were distributed on the surface of the specimen with same magnification, X100. The porosity is then computed at each spot of the captured image. Finally, the porosity of the specimen is represented by the average value of the computed porosity at the investigated spots. As shown in Fig. 5, the isolation process, in which K-means algorithm is adopted to perform the clustering task due to its efficiency and easiness at implementation. The used images in this figure are; a) the original image, b) clustering of similar regions with numbers of colors and c) the isolation of the concerned region in white color, respectively.

Tables 1 and 2 summarize the results of the experiment on a specimen with thicknesses of 10 and $5 \mathrm{~mm}$, respectively. The tables show the original spot image, the clustering process and the isolation process. Based on CVS computations the average value of porosity, for $10 \mathrm{~mm}$ thick specimen is $23.76 \%$ as average of the porosity values in Table 1 . Similarly as in Table 2, the porosity is computed for a specimen with a thickness $5 \mathrm{~mm}$ after removing half of the height in order to estimate the porosity value inside it. The average value of porosity of this specimen as resulted from the computation is $29.04 \%$.

Table 1: Results of extraction of the porosity region of a specimen with $10 \mathrm{~mm}$ thick.

\begin{tabular}{|c|c|c|c|c|c|c|}
\hline Image & Original & Clustered Image & Result & $\begin{array}{c}\text { Black Cluster } \\
\text { Region }\end{array}$ & $\begin{array}{c}\text { Total } \\
\text { Region }\end{array}$ & Ration (\%) \\
\hline 1 & & & & 737946 & 3145728 & 23.45867 \\
\hline 2 & & & & 695444 & 3145728 & 22.10757 \\
\hline 3 & & & & 787568 & 3145728 & 25.03611 \\
\hline 4 & & & & 754486 & 3145728 & 23.98446 \\
\hline 5 & & & & 761418 & 3145728 & 24.20483 \\
\hline
\end{tabular}

As shown in Table 3, the thickness of $\mathrm{Fe}_{3} \mathrm{O}_{4}$ specimens has significant effect on the porosity value. The results show that there is an inverse relationship between the specimen thickness and the porosity ratio, the lower the thickness of the specimen the greater the porosity ratio. This result can be attributed to the processing technique in which the surface of $\mathrm{Fe}_{3} \mathrm{O}_{4}$ specimens was subjected to high pressure, $300 \mathrm{KN}$, which squeezes the material granules together and its value decreases toward the center of the specimen. In general, the resultant internal pressure in the specimen decreases from the surface until it reaches its lowest values at the center of the specimen. As a result, the surface of the specimen is exposed to the highest pressure value, so the $\mathrm{Fe}_{3} \mathrm{O}_{4}$ granules are squeezed and stick together tightly compared to those in the inner region of the specimen. This interpretation is in consistent with the results in Table 3 in which the porosity on the surface of the specimens is $23.76 \%$ and its value is $29.04 \%$ on the removed surface. The average value of porosity of specimen resulted from CVS computation, for both cases, is $26.39 \%$. The results of porosity computations (in average values) are presented in Table 3. This value of porosity indicates that the CVS computation is very close to that resulted from experiments and the difference between the two is very small, which confirms the accuracy of this method. 
International Journal of Engineering Research and Technology. ISSN 0974-3154 Vol.13, No.4 (2020), pp. 653-659

(C) International Research Publication House. https://dx.doi.org/10.37624/IJERT/13.4.2020.653-659

Table 2: Results of extraction of the porosity region of a specimen with $5 \mathrm{~mm}$ thick.

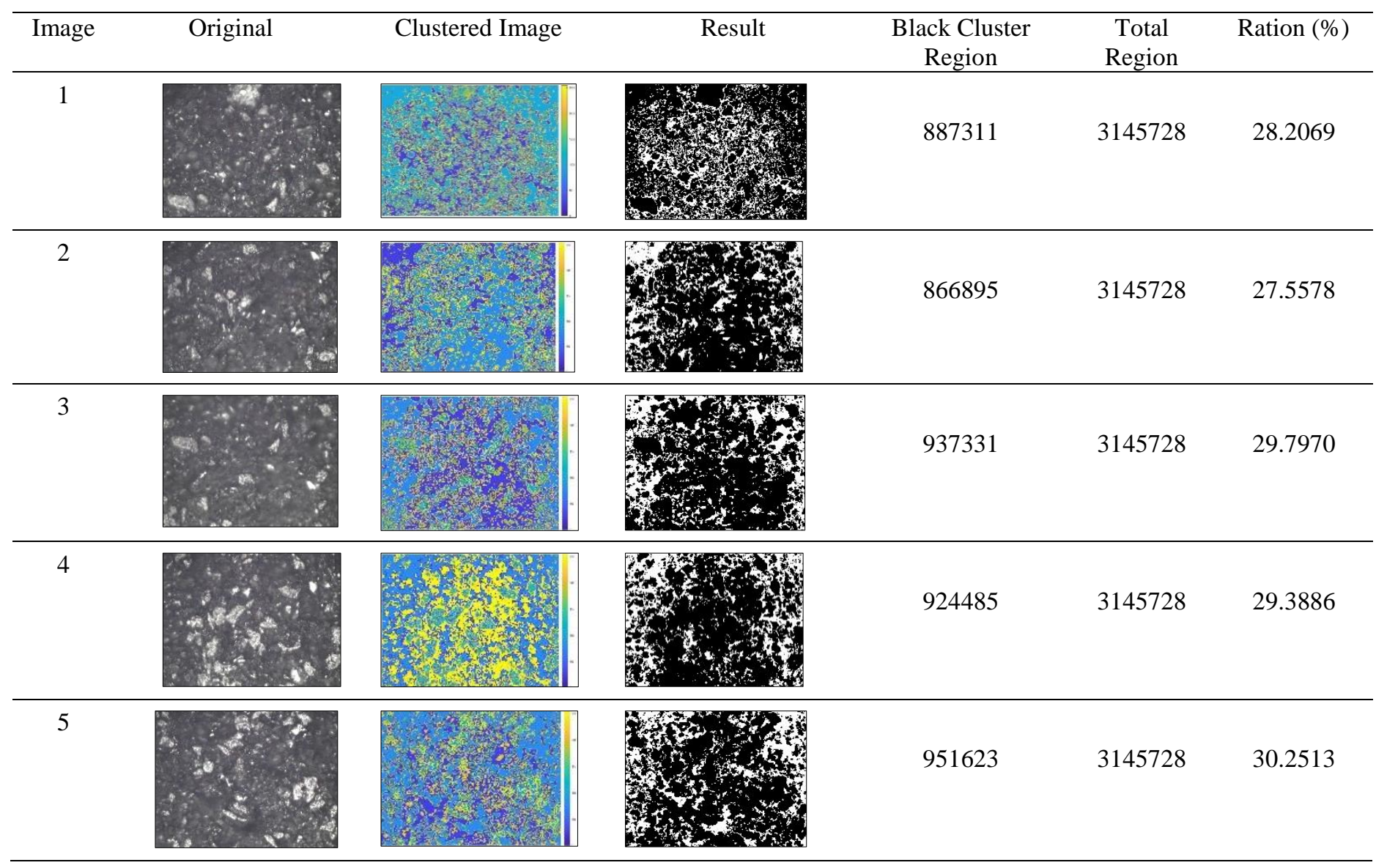

Table 3: The average value of porosity resulted from the CVS computations.

\begin{tabular}{|c|c|c|c|}
\hline Porosity at $10 \mathrm{~mm}$ thick $(\%)$ & Porosity at $5 \mathrm{~mm}$ thick $(\%)$ & Average Porosity of both cases $(\%)$ & True porosity $(\%)$ \\
\hline 23.76 & 29.04 & 26.39 & 26.67 \\
\hline
\end{tabular}

\section{V.CONCLUSIONS}

Based the previous work, porosity has been computed for $\mathrm{Fe}_{3} \mathrm{O}_{4}$ specimens by using CVS in which they were laboratory processed and converted from small granules to solid specimens by PM technique. Two different cases have been considered for porosity computation for specimens with same diameter, $27 \mathrm{~mm}$, and two different thicknesses 10 and $5 \mathrm{~mm}$. $\mathrm{K}$-means clustering algorithm has been applied to the captured images.

1) The average value of porosity of $\mathrm{Fe}_{3} \mathrm{O}_{4}$ specimens was found to be $23.76 \%$ for original specimen with $10 \mathrm{~mm}$ thickness and it increased with decreasing the thickness to be $29.04 \%$. The mean value of porosity for the two computed values of the specimen is $\sim 26.39 \%$

2) Using the conventional method, the porosity of the $\mathrm{Fe}_{3} \mathrm{O}_{4}$ specimens was found to be $26.67 \%$. In comparison between the two methods it is obvious with that the porosity computed by CVS less than that obtained using conventional method with $0.27 \%$.

3) The accuracy of these results obtained from the computation compared to that experiments, indicates the validity and effectiveness of the image processing algorithms in measuring the porosity due to the ease and speed of such a technique.

4) It is recommended for the future that these algorithms be used for a large number of images in a three-dimensional setting, which may enables obtaining more accurate value for porosity compared to that of the traditional method.

\section{Acknowledgments}

The authors gratefully thank the Deanship of Scientific Research at Taif University, Saudi Arabia, for financial support of this study via a research project no: $1 / 438 / 5897$.

\section{REFERENCES}

[1] P.S. Hiremath, A. Sadashivappa, P. Pattan, "Microstructure Image Analysis for Estimating Mechanical Properties of Ductile Cast Iron", Int. J. Comp. Applications, (0975-8887) Vol. 107- No. 17, Dec. (2014), pp. 32-38 
[2] L. Espinal, "Porosity and Its Measurement", Characterization of Materials, ed. by Elton $\mathrm{N}$. Kaufmann, (2012), John Wiley \& Sons, Inc.

[3] P. Prakash, V.D. Mytri and P.S. Hiremath, "Digital Microstructure Analysis System for Testing and Quantifying the Ductile Cast Iron", Intl'. J of Comp Applications, Vol. 19: 3, (2011), pp. 22-27

[4] W.D. Martin, B.J. Putman, "Comparison of Methods for Measuring Porosity of Porous Paving Mixtures", Construction and Building Materials, Vol. 125, (2016), pp. 299-305

[5] J.A. Slotwinski, E.J. Garboczi, and K.M. Hebenstreit, "Porosity Measurements and Analysis for Metal Additive Manufacturing Process Control", J Research of the National Institute of Standards and Technology, Vol. 119, (2014), pp. 494-528

[6] G. Perfetti, E. V. de Casteele, B. Rieger, W. J. Wildeboer, G. M.H. Meesters, "X-ray Micro Tomography and Image Analysis as Complementary Methods for Morphological Characterization and Coating Thickness Measurement of Coated Particles", Advanced Powder Technology, Vol. 21, (2010), pp. 663-675

[7] S. Pan and M. Kudo, "Recognition of Wood Porosity Based on Direction Insensitive Feature Sets", Trans on Mach. Learning and Data Mining, Vol. 5, No. 1 (2012), pp. 45-62

[8] M. N. Qureshi and M. V. Ahamad, "An Improved Method for Image Segmentation Using K-Means Clustering with Neutrosophic Logic," Procedia Computer Science, Vol. 132, (2018), pp. 534-540.

[9] J. Gou, H. Ma, W. Ou, S. Zeng, Y. Rao, and H. Yang, "A Generalized Mean Distance-Based K-Nearest Neighbor Classifier," Expert Systems with Applications, Vol. 115, (2019), pp. 356-372

[10] S. Wazarkar and B. N. Keshavamurthy, "A Survey on Image Data Analysis Through Clustering Techniques for Real World Applications," J of Visual Communication and Image Representation, vol. 55, (2018), pp. 596-626.

[11] J. Qi, Y. Yu, L. Wang, and J. Liu, "K*-Means: An Effective and Efficient K-Means Clustering Algorithm," 2016 IEEE Inter. Conf. on Big Data and Cloud Computing (BDCloud), Social Computing and Networking (SocialCom), Sustainable Computing and Communications (SustainCom) (BDCloudSocialComSustainCom) (2016), pp. 242-249.

[12] S. Guojun, G. Bingkun, and Z. Li, "The Optimized KMeans Algorithms for Improving Randomly-Initialed Midpoints," in Proc. of 2013 2nd International Conf. on Measurement, Information and Control, Vol. 02, (2013), pp. 1212-1216.

[13] K Takahiro, O Yukiko, I Kohji, "Fine Iron Oxide Powder as a Raw Material of Soft Ferrites", JFE Technical Report, No. 6, (Oct. 2005), pp. 29-34

[14] C. Liu , X. Wu, T. Klemmer, N. Shukla, D. Weller, A.G. Roy, M. Tanase, and D. Laughlin, "Reduction of sintering during Annealing of FePt nanoparticles Coated with Iron Oxide", Chem. Mater., 17, (2005), pp. 3620625
[15] M. M. H. El-Sayed M. Saad, Moawad I. Moawad, Mohamed El-Halawany and Alaa M. Abbas, "A New Symmetry Approach for Frontal-View Face Detection," Inter J of Computing, Vol. 6, no. 1, (2007), pp. 25-34. 